\title{
Combination Chemotherapy of Azacitidine and Cetuximab for Therapy-Related Acute Myeloid Leukemia following Oxaliplatin for Metastatic Colorectal Cancer
}

\author{
Akari Hashimoto $^{a}$ Kohichi Takada ${ }^{a}$ Hiroto Horiguchi $^{a}$ Tsutomu Sato ${ }^{a}$ \\ Satoshi Iyama $^{a}$ Kazuyuki Murase $^{a}$ Yusuke Kamihara $^{a}$ Kaoru Ono $^{a}$ \\ Ayumi Tatekoshi $^{a}$ Tsuyoshi Hayashi ${ }^{a}$ Koji Miyanishi ${ }^{a}$ Yasushi Sato ${ }^{a}$ \\ Tomohisa Furuhata $^{b}$ Masayoshi Kobune ${ }^{a}$ Rishu Takimoto $^{a}$ \\ Koichi Hiratab ${ }^{b}$ Junji Kato ${ }^{a}$ \\ Departments of a Medical Oncology and Hematology and ${ }^{b}$ Surgical Oncology and Science, \\ Sapporo Medical University School of Medicine, Sapporo, Japan
}

\section{Key Words}

Therapy-related leukemia $\cdot$ Colorectal cancer $\cdot$ Oxaliplatin $\cdot$ Azacitidine $\cdot$ Cetuximab

\begin{abstract}
Therapy-related leukemia (TRL) has been reported to occur after treatment with alkylating agents and/or topoisomerase II inhibitors. Oxaliplatin (OXP) is used as a key drug for the treatment of colorectal cancer (CRC). Cisplatin and carboplatin have been linked with TRL, but the involvement of OXP is questionable. A 74-year-old male was diagnosed with peritoneal metastasis from CRC in July 2011. The patient received nine cycles of 5fluorouracil (5-FU), leucovorin (LV), and OXP (mFOLFOX-6 regimen) and three cycles of 5-FU and LV only, resulting in a clinical complete response. However, recurrence of CRC was detected by CT within 3 months after the last course of chemotherapy. In April 2013, laboratory tests showed pancytopenia and $15 \%$ blast cells. A bone marrow examination revealed multilineage dysplasia and $20.4 \%$ myeloblasts. Cytogenetic analysis indicated a complex karyotype that included chromosome 5 and 7 abnormalities. The patient was diagnosed with TRL and treated with a combination of azacitidine (AZA) and cetuximab (Cmab) for both cancers. AZA might be useful in TRL when a patient needs to be treated simultaneously for more than one primary cancer because of its low toxicity. Moreover, Cmab
\end{abstract}


Hashimoto et al.: Combination Chemotherapy of AZA and Cmab for t-AML following OXP for Metastatic CRC

is an effective therapeutic tool in TRL patients with metastatic CRC with the wild-type $K$-ras gene.

(c) 2014 S. Karger AG, Basel

\section{Introduction}

Therapy-related leukemia (TRL) is a heterogeneous group of neoplasms that occur as a late consequence of exposure to certain cytotoxic agents and/or radiation therapy for a primary cancer or after immunosuppressive treatment [1]. Alkylating agents and topoisomerase II inhibitors have been implicated in the development of TRL [2]. Oxaliplatin (OXP) is a key drug for the treatment of colorectal cancer (CRC) [3, 4]. The incidence of TRL with the older platinum compounds, such as cisplatin and carboplatin, is well documented [5], but the association of OXP with TRL has not been established. Herein, we report a case of metastatic CRC complicated with OXP-related TRL treated with a combination of azacitidine (AZA) and cetuximab (Cmab).

\section{Case Presentation}

A 74-year-old Japanese male was diagnosed with descending CRC with peritoneal metastasis in July 2011. Immunohistochemical analysis revealed that the resected primary tumor did not express the epidermal growth factor receptor (EGFR). The tumor harbored wild-type $K$-ras, detected by the allele-specific polymerase chain reaction assay. A hematologic examination revealed a white blood cell count of $6,700 / \mu \mathrm{l}, 177,000$ platelets $/ \mu \mathrm{l}$, and a hemoglobin level of $10.4 \mathrm{~g} / \mathrm{dl}$. No atypical cells were seen on the peripheral blood smear examination. The patient was treated with nine cycles of 5-fluorouracil (5-FU), leucovorin (LV), and OXP (mFOLFOX-6 regimen). His peripheral neuropathy developed to grade 3 (CTCAEv4.0) due to OXP toxicity. Accordingly, we changed the regimen to 5-FU and LV only for three cycles, and he achieved a complete response. However, recurrence of CRC was detected by CT within 3 months of the last course of chemotherapy. At the same time, pancytopenia was noted, and he was referred to our department. Blood tests showed the following abnormalities: white blood cell count $2,000 / \mu \mathrm{l}$ with $15 \%$ blasts, platelet count $48,000 / \mu \mathrm{l}$, and hemoglobin $8.8 \mathrm{~g} / \mathrm{dl}$. A bone marrow examination revealed a normocellular marrow with $20.2 \%$ myeloblasts, with an increased ratio between myeloid and erythroid cells, decreased erythropoiesis, and megakaryocytes. Morphologically, 10\% or more of the cells in the three lineages were dysplastic. Bone marrow smears demonstrated a pseudoPelger nucleus, hypogranulated myelocytes, megaloblastic alteration, and micromegakaryocytes. Flow cytometry revealed an abnormal myeloid population expressing CD13, CD33, CD34, and human leukocyte antigen D-related. Chromosomal analyses revealed a complex karyotype, including 46,XY, inv(3)(q21q26.2), del(5)(q13q33), add(7)(q11.2), add(11)(q23), add(15)(p13), and del(16)(q11.1) [2, 4]. Based on these findings, the diagnosis was therapyrelated acute myeloid leukemia (t-AML; M2 morphologic features) with multilineage dysplasia of the WHO classification system. Regarding his CRC, his serum carcinoembryonic antigen and carbohydrate antigen 19-9 levels had increased rapidly, and he was suffering from abdominal pain originating from peritoneal metastasis. The patient was given chemotherapy with AZA, a deoxyribonucleic acid methyltransferase-inhibiting cytosine nucleoside analogue, $75 \mathrm{mg} / \mathrm{m}^{2}$ daily for 5 days every 28 days for t-AML. Moreover, in consideration of the patient's clinical presentation, we offered to use Cmab, an EGFR antagonist, combined with AZA, because his CRC harbored a wild-type K-ras gene. The 
patient agreed to be treated with this combination therapy and received AZA subcutaneously on days 1-5 and Cmab ( $400 \mathrm{mg} / \mathrm{m}^{2}$ for 1 week, followed by weekly doses of $250 \mathrm{mg} / \mathrm{m}^{2}$ ) intravenously on days 8,15 , and 22 , administered every 28 days. He had developed grade 4 hematological toxicity, including neutropenia, anemia, and thrombocytopenia. These adverse effects (AE) were manageable with supportive treatments. Due to AZA administration, the absolute neutrophil count gradually increased. After four cycles of AZA, the patient had stable disease with less than $20 \%$ blasts in the bone marrow. The carcinoembryonic antigen and carbohydrate antigen 19-9 levels also decreased following the first Cmab infusion. This combination therapy achieved stable disease for 5 months (fig. 1). However, the level of the tumor marker began to increase gradually during the third course. The patient was complicated with postoperative adhesive intestinal obstruction and severe aspiration pneumonia after 4 months of this combination chemotherapy. Therefore, he was transferred to a palliative care hospital where he died 7 months later from TRL.

\section{Discussion}

Therapy-related myeloid neoplasms (t-MN) are defined by the WHO as clonal hematopoietic stem cell disorders related to previous exposure to chemotherapy and/or radiation therapy, including myelodysplastic syndromes, t-AML, and myelodysplastic/myeloproliferative neoplasms [6]. Based on the clinical manifestations and morphologic features, there are two subtypes of t-MN. The subtype associated with alkylating agents and/or radiation generally is thought to develop after a latency period of 5-10 years and is accompanied by MDS features and abnormalities of chromosomes 5 or 7 [2]. The other subtype is associated with topoisomerase II inhibitor treatment and presents with symptoms at about 1-3 years after treatment, with generally balanced chromosomal translocations related to $11 \mathrm{q} 23$ or $21 \mathrm{q} 22$, such as $\mathrm{t}(9 ; 11), \mathrm{t}(11 ; 19)$, and $\mathrm{t}(6 ; 11)$, and without MDS manifestations [2]. Platinum-based compounds are effective broad-spectrum anticancer drugs widely used in the treatment of various malignancies. It has been reported that cisplatin and carboplatin have been associated with TRL [5]. On the other hand, the risk of secondary carcinogenesis following treatment with OXP is unclear. In the present case, TRL developed 21 months after OXP administration and harbored a complex karyotype with abnormalities of chromosomes 5 and 7. These clinical manifestations have featured both types of t-MN. The clinical characteristics of 8 patients who developed TRL after treatment with OXP are summarized in table 1 [7-13]. There were 5 male and 3 female patients with a mean age of 64 years (range, 25-79). Regarding the periods of latency of OXP-related t-MN, these have been relatively shorter than those of alkylating agents/radiation and topoisomerase II inhibitor-induced t-MN. The median period of latency to diagnosis of TRL was 19 months (range: 12-29).

The prognosis of t-MN remains dismal. In particular, patients with OXP-related TRL died within 2 months of the diagnosis, except chronic myeloid leukemia cases (table 1). The only curative treatment for t-MN is hematopoietic stem cell transplantation (HSCT). However, tMN patients undergoing HSCT have high treatment-related mortality rates [14]. Generally, HSCT is not feasible in t-MN patients, mostly because of their poor performance status and age. The randomized AZA-001 trial has shown that treatment with AZA significantly increases the overall survival (OS) of patients with higher-risk MDS, except for t-MN patients [15]. Recently, a cooperative Italian group reported a retrospective analysis of $50 \mathrm{t}$-MN patients treated with AZA. The study showed that the overall response rate was $42 \%$ and the median OS was 21 months from the start of AZA [16]. However, the median OS was 16.2 
months for patients with complex karyotypes. These data indicated that AZA treatment might prolong the survival of t-MN patients. AZA is better tolerated than intensive chemotherapy in elderly patients with higher-risk MDS or AML $[17,18]$. Accordingly, treatment with AZA rather than best supportive care should be considered for t-MN patients who are not eligible for HSCT .

The standard AZA administration schedule is $75 \mathrm{mg} / \mathrm{m}^{2} /$ day for 7 days, repeated every 28 days $\left(525 \mathrm{mg} / \mathrm{m}^{2}\right.$ total monthly dose). In the present case, we applied a 5-day AZA schedule ( $375 \mathrm{mg} / \mathrm{m}^{2}$ total monthly dose) because of severe neutropenia and thrombocytopenia. This 5-day schedule delivers approximately 30\% less than the standard dose $(525$ $\mathrm{mg} / \mathrm{m}^{2}$ total monthly dose). It has been reported that a 5-day dose-intensified (500 mg/m² total monthly dose) AZA schedule has similar efficacy to the standard AZA administration regimen [19]. A randomized trial by the Japan Adult Leukemia Study Group is currently in progress and is intended to compare a 5-day schedule of AZA treatment with a 7-day schedule for high-risk MDS. In our case, the patient did not meet the criteria for response, but absolute neutrophil count tended to increase gradually, and the blast count in the bone marrow decreased until the end of his life.

Cmab, a monoclonal antibody against EGFR, has activity against CRC with a wild-type $K$ ras gene [20]. A randomized trial (CO.17) showed that Cmab monotherapy as compared with supportive care alone significantly improves OS (median, 9.5 vs. 4.8 months) and progression-free survival (median, 3.7 vs. 1.9 months) in patients with K-ras wild-type CRC and in whom other treatments had failed [21, 22]. In addition, this therapy preserves the quality of life. Our case survived for 7 months receiving combination chemotherapy. This outcome supported the data of the previous study, showing that Cmab monotherapy improved OS compared with supportive care alone. The most common severe $\mathrm{AE}$ of Cmab are rashes and infections without neutropenia. Cmab does not increase the risk of hematologic AE [21]. Despite our patient suffering from pancytopenia due to TRL, we were able to treat him with Cmab combined with AZA, and he had no severe AE during this treatment. The efficacy of the combination chemotherapy of AZA and Cmab was limited; however, the toxicity was low and tolerable. This combination therapy might be a therapeutic option for pancytopenic t-MN patients with wild-type $K$-ras CRC.

$\mathrm{t}-\mathrm{MN}$ has been recognized as one of the most serious late $\mathrm{AE}$ of cytotoxic therapies in clinical oncology and may be attributed to an improved OS following primary malignancies. Oncologists should carefully check the whole blood count analysis on routine follow-ups, even for asymptomatic patients who have undergone chemotherapy. The incidence and clinical features of OXP-related t-MN should be clarified. Furthermore, the development of effective treatments for $\mathrm{t}-\mathrm{MN}$ is needed urgently.

\section{References}

1 Tefferi A, Vardiman JW: Classification and diagnosis of myeloproliferative neoplasms: the 2008 World Health Organization criteria and point-of-care diagnostic algorithms. Leukemia 2008;22:14-22.

-2 Pedersen-Bjergaard J, Rowley JD: The balanced and the unbalanced chromosome aberrations of acute myeloid leukemia may develop in different ways and may contribute differently to malignant transformation. Blood 1994;83:2780-2786.

-3 Goldberg RM, Sargent DJ, Morton RF, Fuchs CS, Ramanathan RK, et al: A Randomized controlled trial of fluorouracil plus leucovorin, irinotecan, and oxaliplatin combinations in patients with previously untreated metastatic colorectal cancer. J Clin Oncol 2004;22:23-30.

4 de Gramont A, Figer A, Seymour M, Homerin M, Hmissi A, et al: Leucovorin and fluorouracil with or without oxaliplatin as first-line treatment in advanced colorectal cancer. J Clin Oncol 2000;18:2938-2947.

5 Travis LB, Holowaty EJ, Bergfeldt K, Lynch CF, Kohler BA, et al: Risk of leukemia after platinum-based chemotherapy for ovarian cancer. N Engl J Med 1999;340:351-357. 


\begin{tabular}{l|l}
\hline DOI: $10.1159 / 000363100$ & $\begin{array}{l}\text { C 2014 S. Karger AG, Basel } \\
\text { www.karger.com/cro }\end{array}$ \\
\hline
\end{tabular}

Hashimoto et al.: Combination Chemotherapy of AZA and Cmab for t-AML following OXP for Metastatic CRC

6 Swerdlow SH, Campo E, Harris NL, Jaffe ES, Pileri SA, Stein H, Thiele J, Vardiman JW (eds): WHO Classification of Tumors of Haematopoietic and Lymphoid Tissues, ed 4. Lyon, WHO, 2008.

7 Carneiro BA, Kaminer L, Eldibany M, Sreekantaiah C, Kaul K, et al: Oxaliplatin-related acute myelogenous leukemia. Oncologist 2006;11:261-262.

8 Damodaran S, Bellavia T, Sait SN, Wang ES, Wetzler M, et al: Acute myeloid leukemia secondary to oxaliplatin treatment for esophageal cancer. Clin Colorectal Cancer 2012;11:151-154.

$\rightarrow 9$ Merrouche Y, Mugneret F, Cahn JY: Secondary acute promyelocytic leukemia following irinotecan and oxaliplatin for advanced colon cancer. Ann Oncol 2006;17:1025-1026.

10 Merlin F, Prochilo T, Kildani B, Tucci A, Ferrari S, et al: Secondary acute lymphoblastic leukemia following oxaliplatin for adjuvant chemotherapy in colon cancer. Acta Oncol 2008;47:464-466.

11 Vakili-Sadeghi M, Omranpour M: Chronic myeloid leukemia following colon cancer treatment: a case report and literature review. Caspian J Intern Med 2013;4:739-742.

12 Buxhofer-Ausch V, Hinterberger-Fischer M, Hinterberger W: Bcr-abl positive blast crisis of chronic myeloid leukemia emerging in a case of metastatic colorectal cancer 3 months after completion of an 8-month course of cetuximab and irinotecan. Eur J Haematol 2006;76:447-448.

13 Kadikoylu G, Yavasoglu I, Barutca S, Meydan N, Bolaman Z: Chronic myeloid leukemia following the treatment of rectal adenocarcinoma. Med Oncol 2008;25:467-470.

-14 Bally C, Thepot S, Quesnel B, Vey N, Dreyfus F, et al: Azacitidine in treatment of therapy-related myelodysplastic syndrome and acute myeloid leukemia (tMDS/AML): a report on 54 patients by the Groupe Francophone Des Myelodysplasies (GFM). Leuk Res 2013;37:637-640.

15 Fianchi L, Criscuolo M, Lunghi M, Gaidano G, Breccia M, et al: Outcome of therapy-related myeloid neoplasms treated with azacitidine. J Hematol Oncol 2012;5:44.

-16 Fenaux P, Mufti GJ, Hellstrom-Lindberg E, Santini V, Finelli C, et al: Efficacy of azacitidine compared with that of conventional care regimens in the treatment of higher-risk myelodysplastic syndromes: a randomized, open-label, phase III study. Lancet Oncol 2009;10:223-232.

17 Xicoy B, Jimenez MJ, Garcia O, Bargay J, Martinez-Robles V, et al: Results of treatment with azacitidine in patients aged $\geq 75$ years included in the Spanish Registry of Myelodysplastic Syndromes. Leuk Lymphoma 2013, Epub ahead of print

18 van der Helm LH, Scheepers ER, Veeger NJ, Daenen SM, Mulder AB, et al: Azacitidine might be beneficial in subgroup of older AML patients compared to intensive chemotherapy:a single centre retrospective study of 227 consecutive patients. J Hemtol Oncol 2013;6:29.

19 Pierdomenico F, Esteves S, Almeida A: Efficacy and tolerability of 5-day azacitidine dose-intensified regimen in higher-risk MDS. Ann Hematol 2013;92:1201-1206.

20 Ku GY, Haaland BA, de Lima Lopes G Jr: Cetuximab in the first-line treatment of K-ras wild-type metastatic colorectal cancer: the choice and schedule of fluoropyrimidine matters. Cancer Chemother Pharmacol 2012;70:231-238.

-21 Jonker DJ, O'Callaghan CJ, Karapetis CS, Zalcberg JR, Tu D, et al: Cetuximab for the treatment of colorectal cancer. N Engl J Med 2007;357:2040-2048.

22 Karapetis CS, Khambata-Ford S, Jonker DJ, O'Callaghan CJ, Tu D, et al: K-ras mutations and benefit from cetuximab in advanced colorectal cancer. N Engl J Med 2008;359:1757-1765. 


\section{Case Reports in Oncology}

\begin{tabular}{l|l}
\hline Case Rep Oncol 2014;7:316-322 \\
\hline DOI: $10.1159 / 000363100$ & $\begin{array}{l}\text { (c) 2014 S. Karger AG, Basel } \\
\text { www.karger.com/cro }\end{array}$ \\
\hline
\end{tabular}

Hashimoto et al.: Combination Chemotherapy of AZA and Cmab for t-AML following OXP for Metastatic CRC

Table 1. Reported cases of OXP-related leukemia

\begin{tabular}{|c|c|c|c|c|c|c|c|c|}
\hline $\begin{array}{l}\text { First author, } \\
\text { year }\end{array}$ & $\begin{array}{l}\text { Age, } \\
\text { years/ } \\
\text { sex }\end{array}$ & $\begin{array}{l}\text { Type of } \\
\text { leukemia }\end{array}$ & $\begin{array}{l}\text { Primary } \\
\text { site }\end{array}$ & $\begin{array}{l}\text { Chemotherapy } \\
\text { regimen }\end{array}$ & $\begin{array}{l}\text { Onset from } \\
\text { OXP start, } \\
\text { months }\end{array}$ & Karyotype & Treatment & Outcome \\
\hline $\begin{array}{l}\text { Carneiro, } \\
2006 \\
{[7]}\end{array}$ & $56 / \mathrm{F}$ & AML & Cecum & $\begin{array}{l}\text { FOLFOX, FOLFOX and } \\
\text { bevacizumab, LVFU2, } \\
\text { and bevacizumab }\end{array}$ & 28 & Complex $+8(21)$ & $\begin{array}{l}\text { Cytarabine and } \\
\text { mitoxantrone }\end{array}$ & $\begin{array}{l}\text { Died from cecal cancer } 2 \\
\text { months later; AML }\end{array}$ \\
\hline $\begin{array}{l}\text { Damodaran, } \\
2012 \\
{[8]}\end{array}$ & $63 / \mathrm{M}$ & AML & Esophagus & $\begin{array}{l}\text { Capecitabine, OXP, and } \\
\text { radiation }\end{array}$ & 29 & $\begin{array}{l}\text { Complex } \\
\operatorname{add}(5)(q 13), \\
\operatorname{add}(7)(q 32),+8\end{array}$ & $\begin{array}{l}\text { Daunorubicin } \\
\text { and cytarabine }\end{array}$ & $\begin{array}{l}\text { Died from sepsis; acute } \\
\text { obliguric renal failure on } \\
\text { day } 20 \text { of the treatment } \\
\text { course }\end{array}$ \\
\hline $\begin{array}{l}\text { Merrouche, } \\
2006 \\
{[9]}\end{array}$ & $65 / \mathrm{F}$ & APL & Colon & $\begin{array}{l}\text { LVFU2, irinotecan, } \\
\text { LVFU2, and OXP }\end{array}$ & 12 & Complex & - & $\begin{array}{l}\text { Died from APL rapidly } \\
\text { before any specific } \\
\text { treatment was started }\end{array}$ \\
\hline $\begin{array}{l}\text { Merlin, } 2008 \\
{[10]}\end{array}$ & $65 / \mathrm{F}$ & ALL & Colon & FOLFOX & 12 & Not done & - & $\begin{array}{l}\text { Died from bleeding in the } \\
\text { brain rapidly before any } \\
\text { specific treatment was } \\
\text { started }\end{array}$ \\
\hline $\begin{array}{l}\text { Vakili- } \\
\text { Sadeghi, } \\
2013 \\
{[11]}\end{array}$ & $25 / \mathrm{M}$ & $\begin{array}{l}\text { Chronic-phase } \\
\text { CML }\end{array}$ & Rectum & $\begin{array}{l}\text { LVFU2, FOLFOX, and } \\
\text { FOLFIRI }\end{array}$ & 20 & $\begin{array}{l}\text { Philadelphia } \\
\text { chromosome } \\
\text { positive }\end{array}$ & $\begin{array}{l}\text { Imatinib, } \\
\text { palliative } \\
\text { chemotherapy }\end{array}$ & $\begin{array}{l}\text { Achieved a hematologic } \\
\text { response to imatinib but } \\
\text { died from CRC nine months } \\
\text { later; CML }\end{array}$ \\
\hline $\begin{array}{l}\text { Buxhofer- } \\
\text { Ausch, } 2006 \\
{[12]}\end{array}$ & $56 / \mathrm{M}$ & $\begin{array}{l}\text { Biphenotypic } \\
\text { blast crisis of } \\
\text { CML }\end{array}$ & Colon & $\begin{array}{l}\text { Capecitabine and OXP; } \\
\text { cetuximab and } \\
\text { irinotecan }\end{array}$ & 18 & $\begin{array}{l}\text { Philadelphia } \\
\text { chromosome } \\
\text { positive }\end{array}$ & Imatinib & $\begin{array}{l}\text { Achieved a hematologic } \\
\text { response after } 3 \text { weeks }\end{array}$ \\
\hline $\begin{array}{l}\text { Kadikoylu, } \\
2013 \\
{[13]}\end{array}$ & $66 / \mathrm{M}$ & $\begin{array}{l}\text { Chronic-phase } \\
\text { CML }\end{array}$ & Rectum & $\begin{array}{l}\text { Capecitabine, 5-FU } \\
\text { irinotecan, OXP }\end{array}$ & 12 & $\begin{array}{l}\text { Philadelphia } \\
\text { chromosome } \\
\text { positive }\end{array}$ & Imatinib & $\begin{array}{l}\text { Achieved a hematologic } \\
\text { response after } 1 \text { month }\end{array}$ \\
\hline $\begin{array}{l}\text { Present } \\
\text { case }\end{array}$ & $74 / \mathrm{M}$ & AML & Colon & FOLFOX, 5-FU, and LV & 21 & $\begin{array}{l}\text { Complex } \\
\text { inv(3)(q21q26.2), } \\
\text { del(5)(q13q33), } \\
\operatorname{add(7)(q11.2),~} \\
\text { add(11)(q23), } \\
\operatorname{del(16)(q11.1)~}\end{array}$ & AZA and $\mathrm{Cmab}$ & $\begin{array}{l}\text { Died from CRC } 7 \text { months } \\
\text { later; AML }\end{array}$ \\
\hline
\end{tabular}

$\mathrm{ALL}=$ Acute lymphoblastic leukemia; $\mathrm{APL}=$ acute promyelocytic leukemia; $\mathrm{CML}=$ chronic myeloid leukemia; FOLFOX = infusional 5-FU, LV, and OXP; $\mathrm{LVFU} 2=\mathrm{LV}$ plus 5-FU; FOLFIRI = LV, 5-FU, and irinotecan. 
Hashimoto et al.: Combination Chemotherapy of AZA and Cmab for t-AML following OXP for Metastatic CRC

mFOLFOX-6

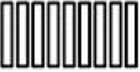

5-FU and LV

III

Azacitidine $75 \mathrm{mg} / \mathrm{m}^{2}$ for 5 days every 28 days

Cetuximab $400 \mathrm{mg} / \mathrm{m}^{2}$ for Week 1 , followed by weekly doses of $250 \mathrm{mg} / \mathrm{m}^{2}$

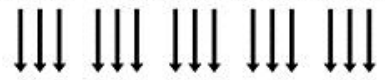

Bone marrow

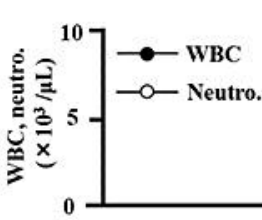

$20.2 \%$

Intint in

Blast cells
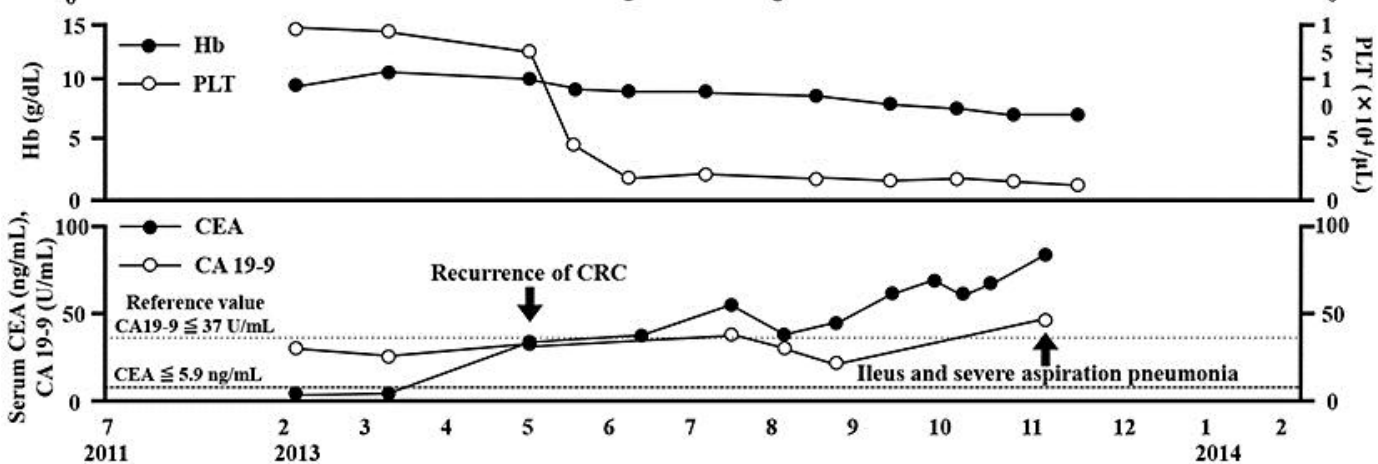

Fig. 1. Clinical course. The patient was diagnosed with peritoneal metastasis from CRC in July 2011. He received nine cycles of the mFOLFOX-6 regimen and three cycles of the 5-FU and LV only regimen, resulting in a clinical complete response. However, he relapsed within 3 months of the end of chemotherapy. In April 2013, laboratory tests showed pancytopenia, and bone marrow aspiration revealed normocellularity with multilineage dysplasia and $20.4 \%$ myeloblasts. He was diagnosed with t-AML. Moreover, his CRC had progressed, and he was treated with a combination therapy of AZA and Cmab. He died 7 months later from TRL. 